\title{
Multi-instrumental characterization of porous media: the role of the Spilling Drop Test
}

\author{
by J. Melada*, P. Arosio*, M. Gargano*, and N. Ludwig* \\ * Dipartimento di Fisica “Aldo Pontremoli”, Università degli Studi di Milano, Via Celoria 16, 20133 Milano, Italy
}

\begin{abstract}
Spilling Drop Test (SDT) is a non-destructive method able to characterize water absorption and diffusion on the surface of building materials through the visualization by passive thermography of the spread of a water drop. This method was used in this research to study the surface characteristics as roughness and open porosity of geo-materials considering different methods of statistical treatment of the wet spreading area. The information acquired by SDT was compared with two standardized methods: the saturation test and the capillary absorption test. In order to test the proposed methods a set of ancient roman plaster and modern mocks-up where analysed.
\end{abstract}

\section{Introduction}

Building materials consist mainly of porous systems with high surface-to-volume ratio [1]. Many properties of building materials such as mechanical strength, durability and moisture transport depends on porosity and on pore network geometry [2]. Recently, many studies have been conducted on the determination of hygric properties of building materials [3] in order to improve diagnostic methods and prevent damages and decay of façade or valuable surface (mosaic and frescoes) [4-5]. Nevertheless, porosity and hygric properties itself are quite difficult parameters to define due to the complexity of phenomena involved in the interaction liquid water-material [2]. Many standards in the building science provide relatively long measuring time and they required homogeneous materials both in shape and composition [3]. Moreover, they usually provide invasive measurements since they require a certain amount of sampled material. In the past years, the spilling drop test (SDT) have been proposed to estimate the hygric behaviour of materials surface and their treatments [6-7]. The main advantages of this method are non-invasiveness, in situ applicability and no need of a-priori knowledge of the homogeneity of the material volume [8]. Classically, a spilling drop acquisition consist in 10 minutes of thermographic image capture of one drop of distilled water (about $0.03 \mathrm{ml}$ ) spilled on the horizontal surface of a material (Fig. 1) [9]. Thermal images display the drop spreading on the surface according to the physical features of the material. The wet area of the surface, detectable by IRT thanks to evaporative cooling, is the parameter studied which leads to an evaluation of the porosity and/or surface roughness of a material. Indeed, the rate of spreading and the geometric shape of the damp area have been seen depended mainly on the porosity of the material [8]. In this work we analyse the potential of the SDT to obtain in a non-invasive and automatic way a set of specific information about porous media. Thereby, one of the main scopes of the proposed method is to develop an automatic algorithm for the processing of SDT data and to evaluate its relationship with traditional standardized techniques.

\section{Materials and methods}

The tests have been performed on mock-ups and on archaeological Roman plaster samples (Table 1). Mock-ups were realized using putty-lime plaster, Portland cement and plaster with powdered bricks ("cocciopesto"). The archaeological samples come from a Roman site situated near the centre of the city of Calvatone (CR - Italy) which is identified with the ancient commercial vicus of Bedriacum. Its foundation dates to the second half of the 2 nd century BC. The main hygric properties have been studied with the least invasive methods, accordingly to the peculiar characteristics of the materials. Beside the laboratory mock-ups we also considered real archaeological samples since they often present many issues e.g. multi-layered fragments, irregular shapes and different dimensions that are not specifically considered in standard methodologies. The 6 selected samples in this work were chosen as the most representative of the various compositional differences found. Three of them are painted (RA1, RA2 and RA3), one is representative of pure cocciopesto plaster (RCp) and one is painted cocciopesto (RAr) and one is putty lime plaster (RMa).

\subsection{Spilling drop test}

The thermograms sequences were acquired using the FLIR A65 thermographic camera placed at a constant distance of $16 \mathrm{~cm}$ from the sample surface. The water drop $(3 \mu \mathrm{l})$ with a temperature of about $21^{\circ} \mathrm{C}$ was poured onto the materials by means of a micropipette. SDT have been carried out in using two data acquisition methods and 3 image processing algorithms. An important and new step that was added in the traditional procedure was to increase the frequency of acquisition in the first few seconds after the drop deposition. This novelty is of fundamental importance considering the fast interaction phenomena in water absorption. Image acquisition was made for $30 \mathrm{~s} @ 10 \mathrm{~Hz}$ (Method 1) in order to reach a trade-off between amount of acquired data, time of the analysis and computational processing cost. 
This method has been compared to the traditional method reported in literature: $600 \mathrm{~s}$ with $1 \mathrm{~Hz}$ framerate (Method 2) [8]. However, as it will be discussed later the information that can be extracted after $300 \mathrm{~s}$ are of negligible value due to the low signal-to-noise $(\mathrm{S} / \mathrm{N})$ ratio of the thermographic image, therefore in this paper data will be presented for a $300 \mathrm{~s}$ time interval. All the work was carried out at a temperature of around $22 \pm 3{ }^{\circ} \mathrm{C}$ and a relative humidity of $53 \pm 6 \%$.

Table 1. Specimens and samples used in this work (Arial, 9 pt, centered, italic)

\begin{tabular}{|c|c|c|c|c|c|}
\hline Name & Description & & & & \\
\hline IC & $\begin{array}{l}\text { Modern plaster with } \\
\text { lime putty, natural } \\
\text { micro-pozzolane, } \\
\text { cocciopesto and } \\
\text { calcareous/siliceous } \\
\text { aggregates }\end{array}$ & $\overline{\mathrm{MA}}$ & $\begin{array}{l}\text { Modern Portland } \\
\text { cement and sand }\end{array}$ & $\overline{\mathrm{ME}}$ & $\begin{array}{l}\text { Commercialy } \\
\text { available plaster } \\
\text { consisting of lime } \\
\text { putty and sand }\end{array}$ \\
\hline & $\begin{array}{l}\text { Yellow and red ochre } \\
\text { pictorial film on fine } \\
\text { cocciopesto layer and } \\
\text { a layer of coarse putty } \\
\text { lime plaster }\end{array}$ & & $\begin{array}{l}\text { Yellow ochre } \\
\text { pictorial film on layer } \\
\text { of fine putty lime } \\
\text { plaster and layer of } \\
\text { coarse putty lime } \\
\text { plaster }\end{array}$ & $\mathrm{RAr}$ & $\begin{array}{l}\text { Red ochre pictorial } \\
\text { film on fine } \\
\text { cocciopesto layer } \\
\text { and fine putty lime } \\
\text { plaster }\end{array}$ \\
\hline$F=$ & $\begin{array}{l}\text { Lead white pictorial } \\
\text { film on layer of fine } \\
\text { putty lime plaster and } \\
\text { a layer of coarse putty } \\
\text { lime plaster }\end{array}$ & $\mathrm{RCF}$ & $\begin{array}{l}\text { One layer of fine } \\
\text { cocciopesto o a } \\
\text { layer of fine putty } \\
\text { lime plaster }\end{array}$ & & $\begin{array}{l}\text { One layer of putty } \\
\text { lime plaster }\end{array}$ \\
\hline
\end{tabular}

The temperature matrix of the thermograms were firstly cropped around the drop in order to obtain a $100 \times 100$ pixel image and they are subsequently converted to 8-bit grayscale. The images were denoised preserving the edges using a bilateral gaussian filter [9]. Subsequently the drop were automatically segmented exploiting 3 different automatic histogram-based thresholding algorithm (Otsu's method [10], Li's method [11] and Yen'method [12]) in order to extract the area of the drop from the images and represent it proficiently. The thresholding methods were compared according to a busyness criterion as suggested in [13] using the co-occurrence matrix of the grayscale image. Indeed, it is assumed that the drop would present a simple compact non-textured shape during the spreading up untill its evaporation or absorption by the material itself. The area of each drop was calculated for all the thermographic sequences using the three aforesaid thresholding algorithms. The pattern of each drop in time was extracted filtering the data with a moving average filter with 15 datapoints window size in order to remove the noise.
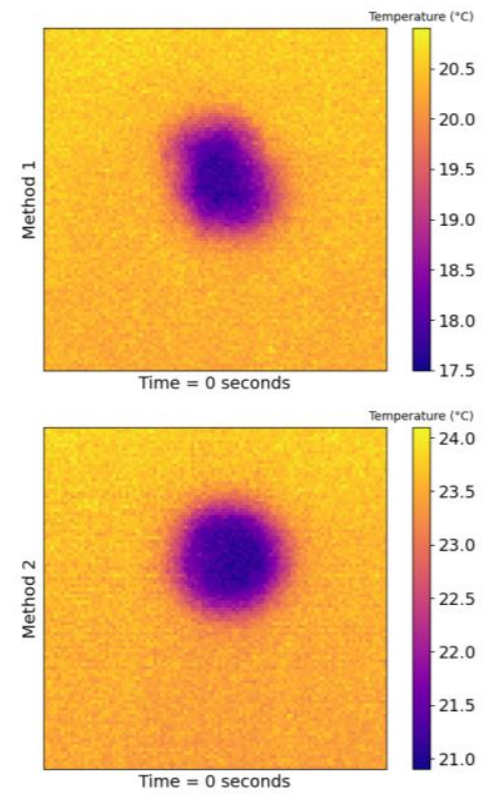
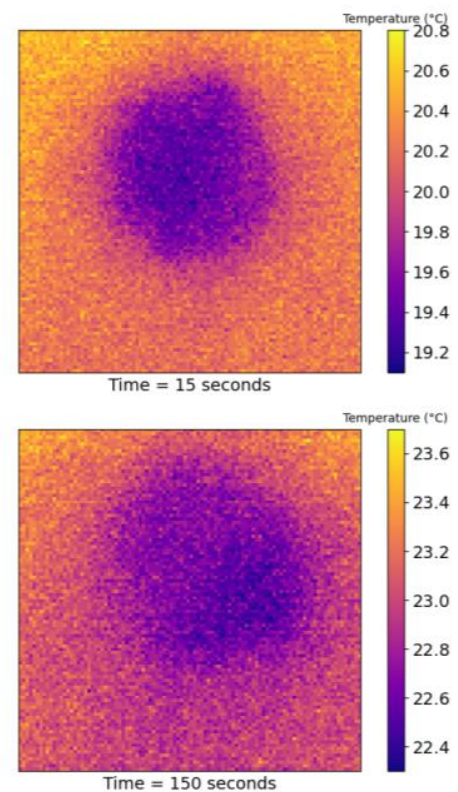
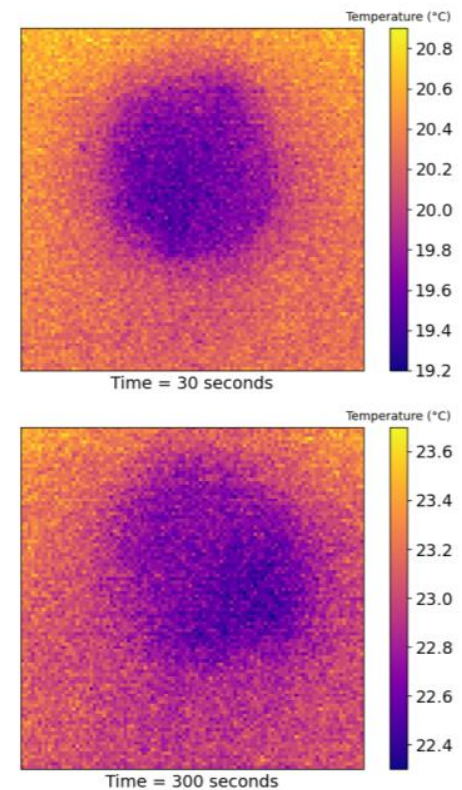

Fig. 1. Water drop spreading on sample surface during method 1 (upper line) and method 2 (bottom line) acquisition strategy 
Finally, the relative increase of each drop with respect to its initial value were computed from the trend in order to not consider the fluctuations due to thermal instability

\subsection{Saturation tests and capillary absorption test}

SDT data have been compared with hygric properties of the considered samples: moisture content (MC), open porosity $(\Phi)$ and capillary absorption index (Acap). MC was determined by oven-dry gravimetry as recommended by many standards [15]. It is expressed as percentage in the ratio of the mass of water inside the specimen to the mass of the dry specimen [16].

The saturation or immersion technique determines porosity of a material by saturating a specimen with a liquid of known density and calculating the pore volume from the weight difference between the fully saturated and dry condition [15]. Deionized water was used as saturating fluid. Prior to saturation mock-ups and samples were kept in vacuum of about $5 \mathrm{k} \mathrm{Pa}$ for 6 hours in a vessel with silica gel. Then they were saturated with deionized water under vacuum for one week. The weight of the saturated mock-ups and samples is determined after the excess of water is removed from their surfaces. The density of the saturating liquid was determined according to Kulia et al. [16]

The capillary absorption test, or water uptake test, determines the capillary absorption coefficient (Acap ). It was measured according to the one-tanged method as described in [3]. The samples, which are previously oven-dried, were weighted every minute in order to measure the amount of water absorbed by capillary rising through the surface of samples in contact with deionized water. The same surface of the samples tested by SDT was used in order to evaluate Acap. All the aforementioned tests had been performed after that the specimens were oven-dried for one night at $103^{\circ} \mathrm{C}$ in order to remove all fluids in pores.

\section{Results and discussion}

The liquid water areas are clearly visible via infrared thermography thanks to evaporative cooling of the surface of all the materials for both the acquisition methods (method 1 and method 2), an example can be seen in Fig. 1. It is important to consider that the water spreading in common geo-materials is faster than the heat diffusion as reported in [8] and in our images the heat diffusion is indeed associated to the mass transport in the initial phase of the trial. However, it should be noted that the absorption of the drop by the material occurs in all directions; the parameter of interest is therefore the evolution of the drop area on the material due to the transport of the liquid in the open surface pores. During the observation time considered it was difficult to observe and distinguish the vertical capillary absorption and the evaporation rate of the drop itself. These two parameters limit the observation of the phenomenon of horizontal spreading due to the absorption of the material during the first minutes of observation, then the contrast between the lowering of the surface temperature of the wet and surrounding dry material becomes negligible and it is no longer possible to distinguish the drop area due to the low temperature differences.
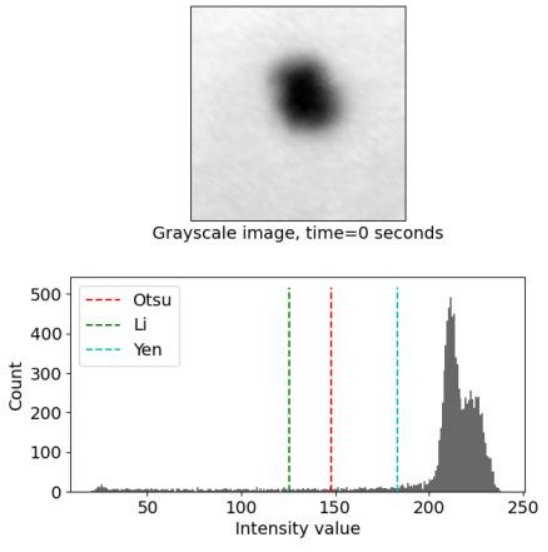

Otsu thresholding Li thresholding Yen
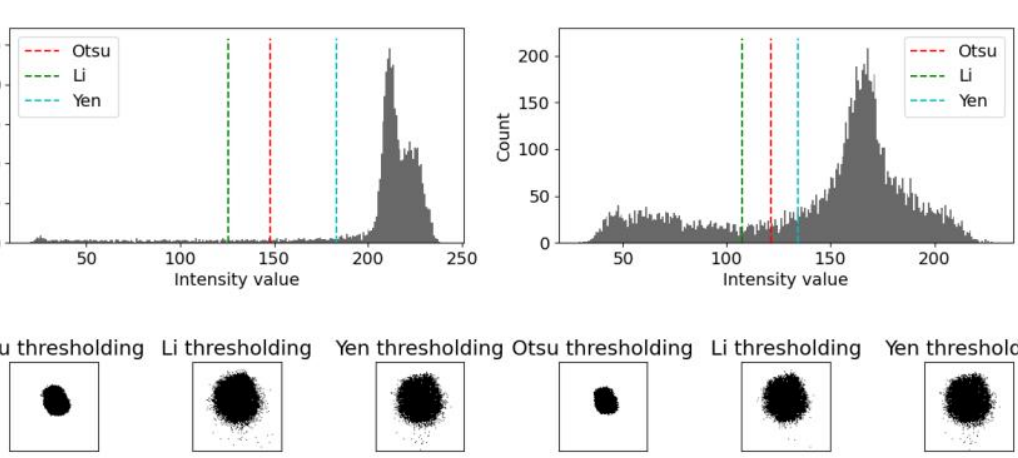

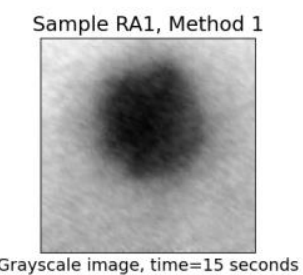

Li thresholding
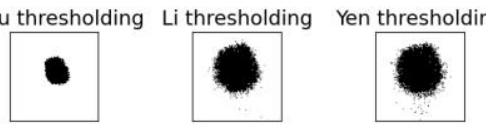

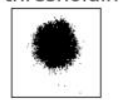

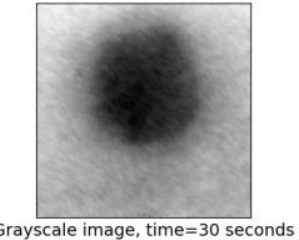

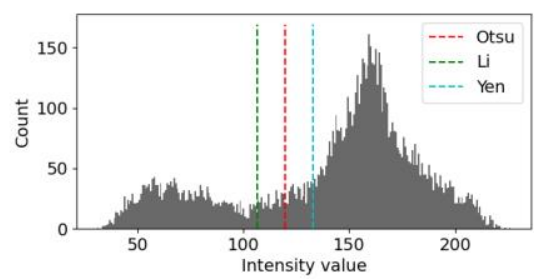

Intensity value

Fig. 2. Methods to obtain automatically the segmentation of the wet area of the drop at different time by using popular histogram-based segmentation algorithms (Otsu, Li and Yen) 
In previous works the thermogram at maximum wet area extension (visually identified by the operator) was utilised to characterize the materials through the relative increase of the wet area with respect to the moment of the drop deposition $[8,9]$. The areas were calculated approximating them with a circle having diameter equal to the plateau of colder temperature (i.e. maximum thermal gradient along a profile crossing the sample). In this work we propose a method to automatically obtain the pattern of the drop area using consolidated segmentation algorithms. In this way, both the drop's size and the time were considered [8].

During the first 30 seconds after the drop deposition, the drop area increases (Fig. 2, first row) driven by chemical and mineralogical composition of the samples that influence the surface hydrophilicity, and by pores network characteristics (amount, radius, dimensional distribution and shape) [8]. The histogram of the grayscale images (Fig. 2, second row) changes in time making it difficult to reconstruct the boundary of the drop due the loss in thermal contrast between wet and dry areas. The histogram of the images changes during time passing from unimodal distributions with a relatively higher abundance of light pixel left-skewed to a bimodal histogram. In the third row of the same figure are shown the results for the different methods of automatic segmentation considered: Otsu [10], Li [11] and Yen [12]. In the figure it is possible to compare the main differences in their operating principles.
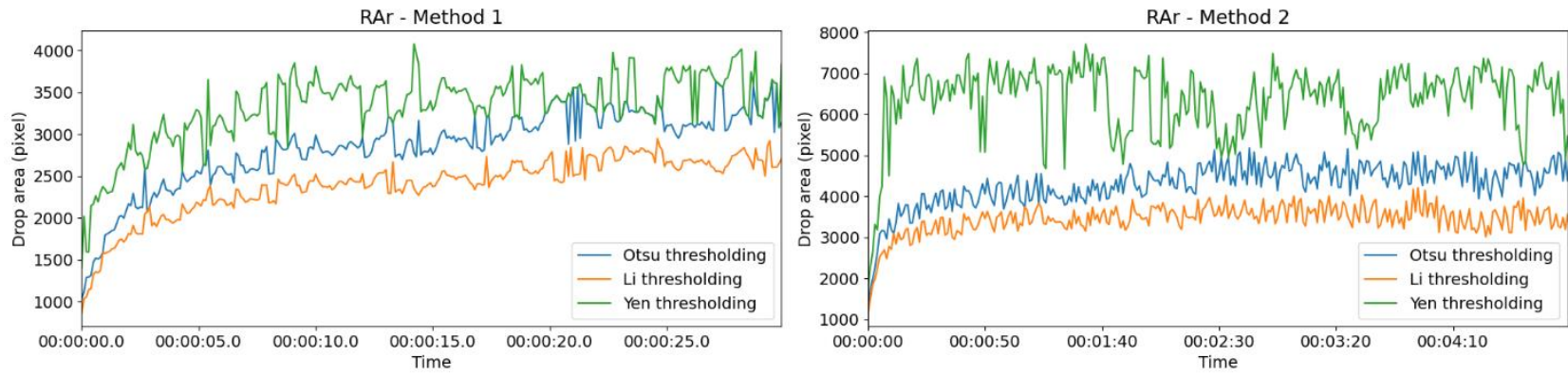

RA3 - Method 1
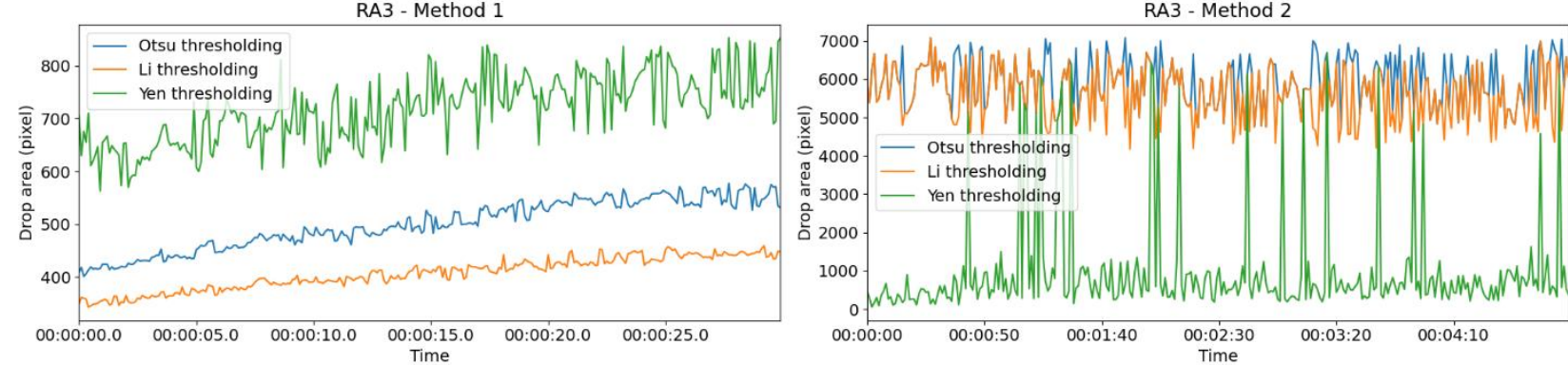

Fig. 3. Raw area increases of two representative samples Rar and RA3

Fig. 3 shows the raw area increase of two representative samples (RAr and RA3). As can be seen the first $30 \mathrm{~s}$ of analysis (method 1) shows less signal-to-noise ratio (SNR) and a more distinguishable pattern of the area in time than method 2. Since there are no ground truth measurements for the area all the thresholding algorithms are considered for further data analysis. As an indication for the quality/validity of segmentation obtained, it was added a busyness index method that uses the co-occurrence matrixes of all the thermograms. The busyness index was calculated for each grayscale image summing the co-occurrence matrix's entries that represent the percentage of object-background adjacencies. Comparing the distributions of the busyness index, a higher busyness index would suggest a large amount of noise or areas with jagged edges. Fig 4 shows the busyness index distribution for all the time sequences acquired with method 1 for all the samples and all the thresholding algorithms. As can be seen, all the studied methods have a similar amount of busyness in images presenting all the interquartile range below 10 units of busyness with few exceptions. Overall it seems that Yen's method performs a better segmentation. Due to the more rapid acquisition set-up, less noise data and more easily observable trend and we will continue to discuss the results obtained with method 1 using all the threshold methodologies. In order to remove the uncertainties due to the differences in the drop's area calculated using different algorithms, we express the evolution of the drop on the surface as the ratio of the drop to the initial value after it was poured on the surface. The relative increases, express as percentage, demonstrates less variability than in the raw areas. To classify the obtained curves, we observed the values at 30 seconds by estimating the central tendency of the 3 algorithms, after which the increases become constant (Fig 5). We classified 3 classes: class A includes those materials whose relative increase in the drop area at 30 seconds is $<50 \%$. For this case the material is not very absorbent, and the water does not spread. An example of the behaviour of this class is reported in Fig. 3 (lower) for the sample Ra3, it is interestingly to stress that none of the modern mock-up, even if built with different materials show a similar trend in area increase. Class $B$ includes materials that have a relative increase of between 50 and $200 \%$. These are materials on which the drop expands to triple their initial area. Finally, class $C$ includes all the materials above which the drop increases more than 3 times the initial volume. 


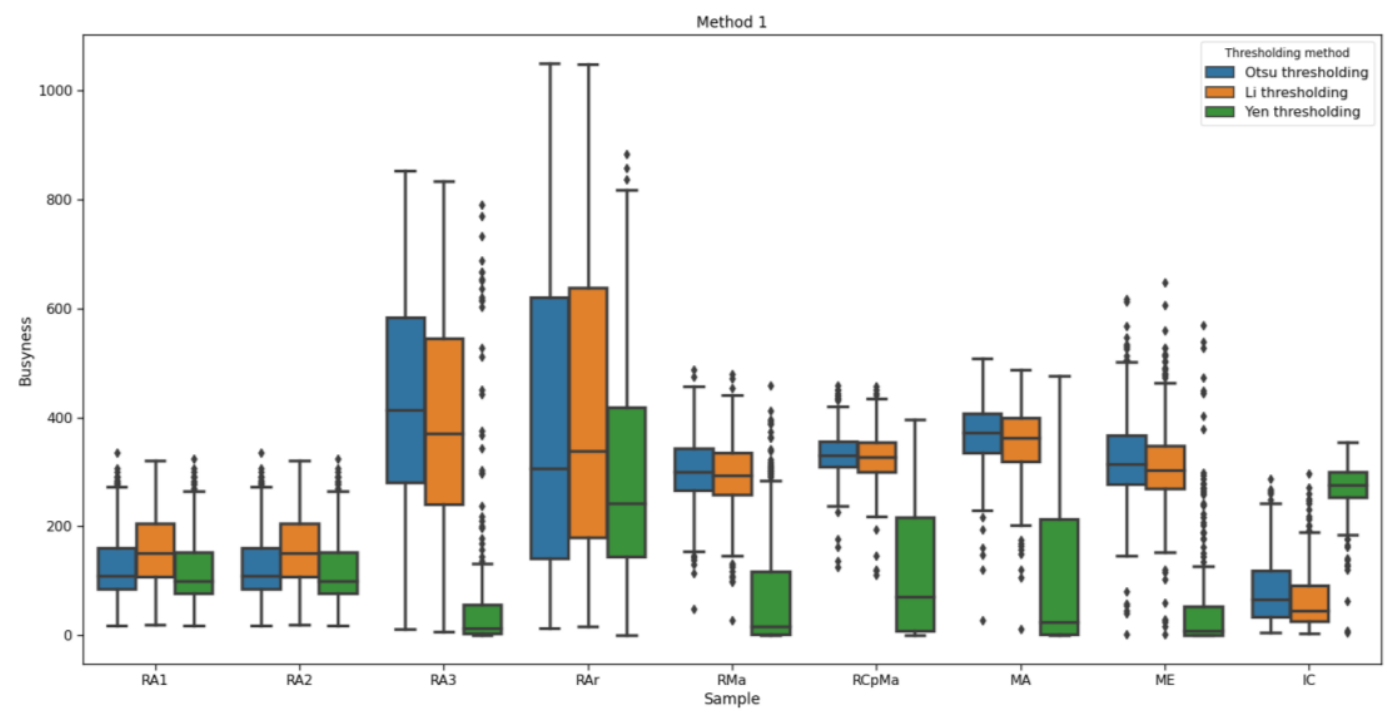

Fig. 4. Busyness index evaluated for method 1

Comparing the results obtained with the hygroscopic parameters of the selected materials, however, no significant correlations were obtained confirming us that drop spreading over the surface (and consequently SDT) is a different diagnostic method with respect to the gravimetric ones (Table 2). This suggests that spilling drop is not an optimal method for obtaining information about the capillary absorption or porosity of the materials as it typically provides only superficial and non-volumetric indications, unlike the other hygroscopic parameters. However, it could be very interesting to use the proposed procedure (method 1) to evaluate the possibility of using infrared thermography to estimate the wettability or surface roughness of the materials and the capillary network in the very superficial layer where the most important interactions and energy exchanges between geo-material and air occur.
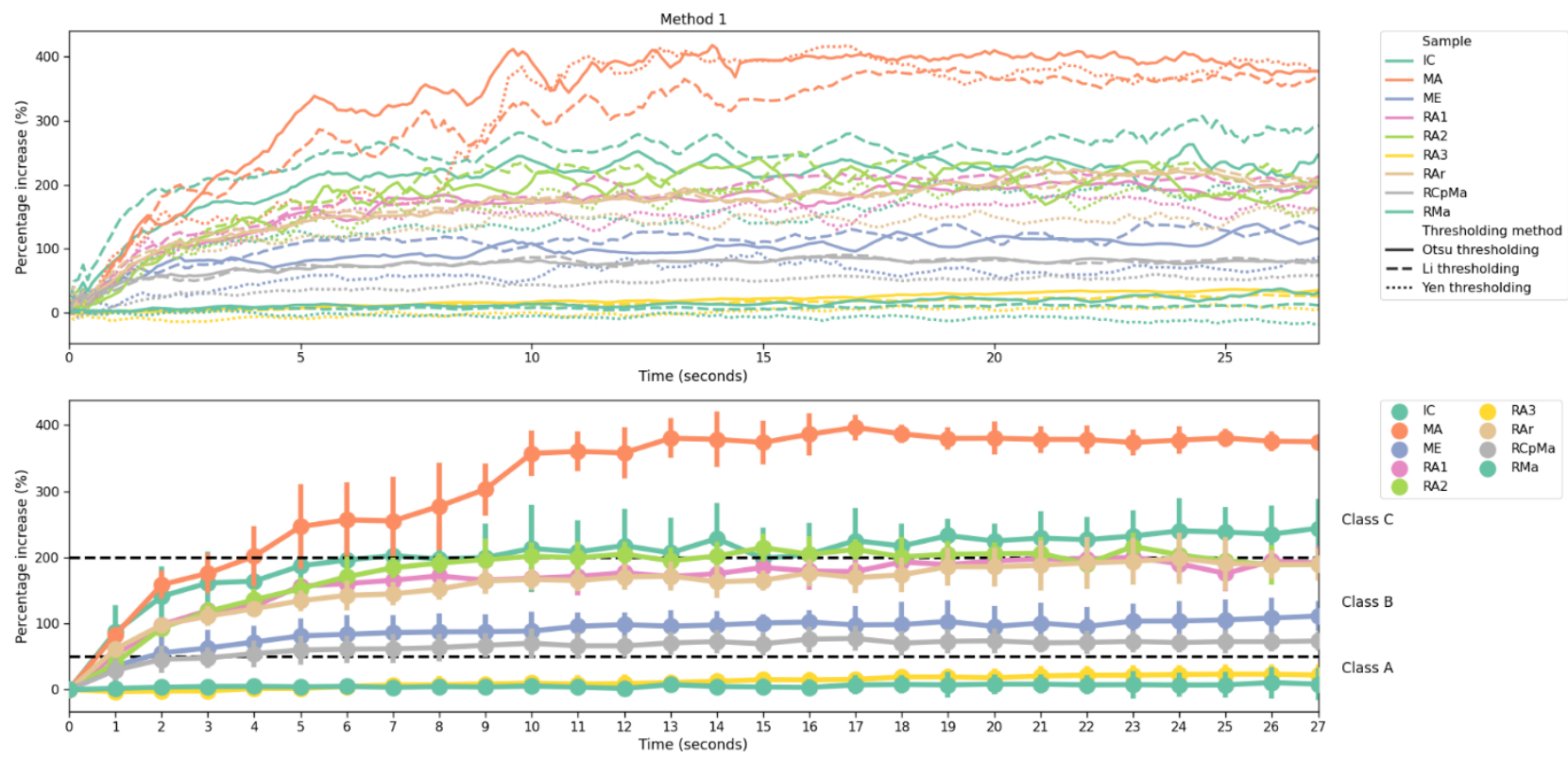

Fig. 5. Percentage increase of the drop areas during for the first method (30"). The error bars represent one sigma error on threshold method 


\section{Conclusions}

Spilling drop test has been proved to highlight/detect different behaviour of water spreading in building materials such as plaster. Our test demonstrate that the first $30 \mathrm{~s}$ and a high sampling rate are the most important parameter to allow a classification of materials due both to rapidity in capillary suction and the duration of the cooling of drop evaporation. A complete comparison of automatic segmentation algorithm we studied finding that in terms of percentage/relative area increase all the considered methods are able to correctly extract the significant features.

The tests have been performed on ancient roman plaster, representative of sample that cannot be manipulated in destructive way and that represents a very interesting filed linking archaeology, modern non-destructive techniques and civil building material characterizations [18]. we obtained a preliminary result that describe them as very resistant material with very low percentage spreading, possibly connected to the high technology reached by the ancient Romans in this field [19].

Table 2. comparison among specimens and samples characteristics considered in this work.

\begin{tabular}{|l|l|l|l|l|}
\hline Sample & MC $(\%)$ & $(\%)$ & Acap & SPT Class \\
\hline RA1 & 29.46 & 41.28 & 0.39 & B \\
\hline RA2 & 17.51 & 28.6 & 0.16 & B \\
\hline RA3 & 17.57 & 29.29 & 0.26 & A \\
\hline Rar & 32.75 & 45.12 & 0.3 & B \\
\hline RCpMa & 25.51 & 40.65 & 0.43 & B \\
\hline RMa & 24.84 & 37.96 & 0.25 & A \\
\hline MA & 21.7 & 36.71 & 0.32 & C \\
\hline ME & 20.58 & 31.82 & 0.36 & B \\
\hline IC & 26.6 & 38.03 & 0.28 & C \\
\hline
\end{tabular}

\section{REFERENCES}

[1] Brai M., Casieri C., De Luca F., Fantazzini P., Gombia M., Terenzi, C., "Validity of NMR pore-size analysis of cultural heritage ancient building materials containing magnetic impurities". Solid state nuclear magnetic resonance, vol. 32(4), pp. 129-135, 2007.

[2] Anovitz L. M., Cole D. R., "Characterization and analysis of porosity and pore structures". Reviews in Mineralogy and geochemistry vol. 80.1, pp. 61-164, 2015

[3] Feng C., Janssen H., Feng Y., Meng Q, "Hygric properties of porous building materials: Analysis of measurement repeatability and reproducibility". Building and Environment, vol. 85, pp. 160-172, 2015.

[4] Melada, J., Arosio, P., Gargano, M., Veronese, I., Gallo, S., \& Ludwig, N. (2020). Optical reflectance apparatus for moisture content determination in porous media. Microchemical Journal, 154, 104627.

[5] Capineri, L., Capitani, D., Casellato, U., Faroldi, P., Grinzato, E., Ludwig, N., ... \& Ruggeri, R. (2011). Limits and advantages of different techniques for testing moisture content in masonry. Materials Evaluation, 69(1), 111116.

[6] Rosina, E., Ludwig, N., Torre, S. D., D'Ascola, S., Sotgia, C., \& Cornale, P. (2008). Thermal and hygroscopic characteristics of restored plasters with different surface textures. Materials evaluation, 66(12), 1271-1278.

[7] Sansonetti, A., Casati, M., Rosina, E., Gerenzani, F., Gondola, M., \& Ludwig, N. (2012). Contribution of IR thermography to the performance evaluation of water repellent treatments. Restoration of Buildings and Monuments, 18(1), 13-22..]

[8] Ludwig N., Rosina E., Sansonetti A., "Evaluation and monitoring of water diffusion into stone porous materials by means of innovative IR thermography techniques". Measurement, vol. 118, pp. 348-353, 2018

[9] Garrido, I., Lagüela, S., Sfarra, S., Madruga, F. J., \& Arias, P. (2019). Automatic detection of moistures in different construction materials from thermographic images. Journal of Thermal Analysis and Calorimetry, 138(2), 1649-1668.

[10] Xu, X., Xu, S., Jin, L., \& Song, E. (2011). Characteristic analysis of Otsu threshold and its applications. Pattern recognition letters, 32(7), 956-961.],

[11] Li's method [Li, C. H., \& Tam, P. K. S. (1998). An iterative algorithm for minimum cross entropy thresholding. Pattern recognition letters, 19(8), 771-776.]

[12] Yen, J. C., Chang, F. J., \& Chang, S. (1995). A new criterion for automatic multilevel thresholding. IEEE Transactions on Image Processing, 4(3), 370-378.

[13] Weszka, J. S., \& Rosenfeld, A. (1978). Threshold evaluation techniques. IEEE Transactions on systems, man, and cybernetics, 8(8), 622-629.

[14] D. Camuffo, Standardization activity in the evaluation of moisture content, J. Cult. Herit. 31 (2018) S10-S14. doi:10.1016/J.CULHER.2018.03.021. 
[15] EN 16682 Conservation of Cultural Heritage - Methods of Measurement of Moisture Content, or Water Content, in Materials Constituting Immovable Cultural Heritage European Committee for Standardization (CEN), Brussels (2017)

[16] U. Kuila, D.K. McCarty, A. Derkowski, T.B. Fischer, M. Prasad, Total porosity measurement in gas shales by the water immersion porosimetry (WIP) method, Fuel. 117 (2014) 1115-1129.

[17] Feng, C., \& Janssen, H. (2018). Hygric properties of porous building materials (III): Impact factors and data processing methods of the capillary absorption test. Building and environment, 134, 21-34.

[18] Bartz, W., Rogóż, J., Rogal, R., Cupa, A., \& Szroeder, P. (2012). Characterization of historical lime plasters by combined non-destructive and destructive tests: The case of the sgraffito in Bożnów (SW Poland). Construction and Building Materials, 30, 439-446.

[19] Al-Bashaireh, K. S. (2008).Chronology and technological production styles of Nabatean and Roman plasters and mortars at Petra (Jordan). The University of Arizona.

[20] Melada, J., Gargano, M., Veronese, I., \& Ludwig, N. (2018). Does electro-osmosis work in moisture damage prevention? Applicability of infrared-based methods to verify water distribution under electric fields. Journal of Cultural Heritage, 31, S38-S45. 